\title{
Path Dependence in Neoclassical Economic Growth Theory
}

\author{
A. JAKIMOWICZ \\ Institute of Economics, Polish Academy of Sciences, \\ pl. Defilad 1, PL-00901 Warsaw, Poland
}

\begin{abstract}
Path dependence is a key feature of complex economic systems. It implies that history matters in the long-term evolution of markets and economies. Path dependence can be viewed as the dynamic version of positive feedback effects. This paper focuses on the nonlinear neoclassical economic growth model with the Cobb-Douglas production function, which accounts for problems related to pollutant emissions. It was found that only selected initial forms have a chance to develop. Present states depend on past states, even though the historical circumstances that had affected the past states may no longer be relevant. The choice among different histories may be a stochastic process. The understanding of economic growth suggested in this study stands in opposition to the neoclassical tradition based on equilibrium states or paths independent of the system's history. In contemporary economics, the idea of path dependence is most often used in studies on the high-tech industry, where the researchers are focused on such phenomena as innovation processes, monopolization, or the causes of ineffective technical solutions. The analysis of historical conditions is almost entirely carried out with the use of qualitative methods, since the subject of the research is non-formalized. In addition, the theoretical basis for conducting relevant empirical research is still missing. As a result of the development of complexity economics in recent years, numerous dynamic features of complex economic systems can be examined with the application of quantitative methods which, in effect, strengthens the bonds between theory and practice. Rare exceptions include path dependence relations. The aim of this article is to fill this gap and to create a theoretical basis for quantitative research on historical conditions in economics. This is a necessary condition for undertaking empirical research. The theoretical search started with the Keynesian model of the Samuelson-Hicks trade cycle, to demonstrate that conventional economics completely omits the most interesting path-dependence cases. It turns out that only the neoclassical model of economic growth, taking into account two power laws, provides appropriate dynamic characteristics for a full description of path dependence relations. Therefore, appropriate theoretical bases can be provided only by complexity economics. It may seem that, in this work, the dependence on history is restricted to two successive time steps in the case of the Samuelson-Hicks model and a single step in the neoclassical model of economic growth by Day. However, it examines an ordered path dependence, where events are chronologically ordered and the impact of earlier events on the later ones occurs through intermediary events. It should be remembered that events are constantly affected by environmental stimuli that are reflected not only in initial conditions, but also in the values of the parameters for all periods. Thus, it is not a case of short-term memory.
\end{abstract}

DOI: 10.12693/APhysPolA.127.A-86

PACS: 89.65.Gh, 89.75.-k, 05.45.-a, 07.89.+b

\section{Introduction}

Path dependence is a basic type of market and economic behaviour examined in complexity economics. The concept of path dependence puts emphasis on historical conditions in the long-run evolution of complex economic systems [1]. Most often, it means either permanent maintenance in the economic consequences of individual innovations or the absence of a self-correcting mechanism in the development of individual innovations, through which their outcomes are permanent unless new countervailing innovations appear [2]. Therefore, the idea of path dependence is based on positive feedback effects. The research carried out within this field assumes that the history of institutional economic development is of crucial importance in explaining the evolution of markets and economies. While examining the role of positive feedback effects in economics, it is emphasized that the main sources of economic process ineffectiveness are increasing returns and network externalities [3-5]. As a consequence, in path-dependent economies, development lock-in by historical events may occur $[6,7]$. Therefore, economies may find themselves in certain developmental traps, the way out from which is only possible through the intervention of a certain external force or a developmental shock. Such phenomena may change the nature of the system or transform mutual relations between business entities. The occurrence of path dependence indicates the existence in economic systems of various equilibrium points, whose reaching may depend on various fortuitous events. The reaching of such points does not have to mean the occurrence of optimal states. Systems may sometimes find themselves on undesirable trajectories and reach states that endanger their existence.

The concept of path dependence finds various applications in economic sciences. It is used in economic geography [8], in analyses of decision-making processes [9, 10], housing policy [11] and organizational theory [12-14] and is useful in examining institutional changes in the development of a welfare state [15] and has significance in financial markets, where it facilitates the pricing of a certain class of financial contracts, i.e. pathdependent financial instruments [16]. Since path dependence is a feature of many complex systems, its application is not limited only to economical sciences. Increasingly more studies appear in such disciplines as sociology 
or political sciences, where many phenomena cannot be properly explained without taking into account historical events [17, 18]. The methodological trend is also becoming of interest through related notions in various sciences [19-21]. Path-dependent functions, used as field variables in quantum electrodynamics, are well-known in physics [22].

Empirical research on historical conditions in economics must be preceded with formalization of the issue, which means reference to economic theories seeking to explain path dependence relations observed in the real world. Additionally, the subject of research must be quantified to make empirical analyses possible. The formation of a quantitative basis for examining the path dependence phenomenon in economics is not easy at least for two reasons. First of all, it has been completely omitted by classics of this science, and economic history is limited to only a selective description of some cases. Secondly, the studies concerning the impact of history on the processes of creation and development of innovations do not have a long tradition in the economics. Therefore, those issues are analysed mainly with qualitative methods. In order to determine the theoretical bases necessary to make progress in this field, reference is made to two well-known models: the Samuelson-Hicks model of business cycle fluctuations and the neoclassical model supplemented with two power laws (the Cobb-Douglas production function and an element taking into account the emission of pollution). The first model belongs to conventional economics and the latter to complexity economics. The Samuelson-Hicks model plays the role of a frame of reference and was used to demonstrate that strong and thus the most interesting - path dependence relations cannot be examined on the basis of conventional economics. Therefore, theoretical bases to examine historical conditions can be provided only by complexity economics. The neoclassical model with the production function of a Cobb-Douglas type and an element related to the reduction of efficiency - as a result of emission of pollutions in production processes - was selected because it is one of the least-explored nonlinear economic models. It was developed by Day in the first half of 1980s, and its main role consisted in introducing nonlinearity and deterministic chaos to economics. Additionally, academic circles obviously assumed that it would not contribute anything new to the development of economics, which explains its rare presence in economic literature in subsequent years. The article proves that this model should be considered a milestone in the development of economics because of the extremely broad scope of dynamic phenomena that it may generate. It features many characteristics that are found in much more complex, multi-dimensional systems. At the same time, it is so uncomplicated that it can make a convenient starting point for more advanced quantitative research on path dependence in economics. The article presents various previously unknown dynamic characteristics of this model, such as the coexistence of attractors and repellers, which
- as it has been demonstrated - is the source of the most interesting path dependence phenomena. The correspondence between the coexistence of attractors and repellers in the phase space of dynamical systems and path dependence has not previously been reported in the literature. The article defines a new field of the application of path dependence in economics, namely the issues of economic growth and development. The SamuelsonHicks model includes only dependence on history in the weak version, and it concerns both types of dynamic movements: convergent-to-dynamic equilibrium states, and divergent, when the attractor is a point in infinity. The neoclassical growth model analyses the most interesting cases in attractors and repellers, while divergent trajectories are not examined.

The Samuelson-Hicks trade cycle model features two time lags, while the neoclassical model of economic growth features only one. Nevertheless, it is of no significant importance since the article analyses ordered path dependence. It means that variables are chronologically ordered and the values of variables from previous periods affect the values of the same variables from later periods through the values of intermediate periods. Additionally, the study takes into account the impact of the environment, which determines the values of parameters in all periods. Thus, the analysis is not limited to short-term memory cases only.

\section{Definitions of the Path Dependence}

The literature of the subject provides many definitions of path dependence. From the perspective of this article, the definitions provided by Page are the most useful, as they are of high operational importance [23]. A dynamic process is referred to as path dependent if the outcome of any period depends upon the vector of history and can depend on its order:

$x_{t+1}=O_{t}\left(\boldsymbol{H}_{t}\right)$,

where $\boldsymbol{H}_{t}$ is a vector of historical events, $O_{t}$ represents the outcome function, while $x_{t+1}$ is the outcome of period $t+1$. The outcome of each period can also include additional information on opportunities and events which emerged in that period. Thus, a description of the environment in period $t$ is formed, taking into account exogenous factors affecting the outcomes. A history at time $t$, denoted by $\boldsymbol{H}_{t}$, is a combination of all outcomes $x_{t}$ up time $t$ together with all other factors also up time $t$. A dynamic process also has an outcome function $O_{t}$, which reflects the impact of the current history on the next outcome. Since the outcome function can change over time, it is indexed by $t$. It does not have to be deterministic; it can generate certain probability distribution over outcomes. It should be noted that in case of definition (1), a change of order $x_{1}$ and $x_{2}$ can change the outcome generated by $O_{t}$. In a further part of the article, this type of path dependence is referred to as a weak version. This means that only condition (1) is satisfied, but not condition (2) provided below. 
In some cases, the notion of strong path dependence can be useful [23]. A dynamic process is strongly path dependent if for two different vectors of history, the outcome functions are different. It can be presented in the following form:

$x_{t+1}=O_{t}\left(\boldsymbol{H}_{t}\right), \quad O_{t}\left(\boldsymbol{H}_{t}\right) \neq O_{t}\left(\overline{\boldsymbol{H}}_{t}\right)$ for $\boldsymbol{H}_{t} \neq \overline{\boldsymbol{H}}_{t}$. (2) In other words, two different paths imply various probabilities of outcomes. The properties of strong path dependence result in the path dependence relation. Strong path dependence may be referred to as order of the path dependence. Path dependence relations may not be confused with sensitivity to initial conditions, which is the essence of the deterministic chaos.

In a further part of the article, a dynamic, nonlinear process of economic growth is analysed, taking into account neoclassical postulates. For comparative purposes, the analysis of a neoclassical growth model is preceded by presentation of results concerning a search for path dependence relations in one of the best known dynamic models of conventional economics - the SamuelsonHicks trade cycle model. In both cases, conventional and complex neoclassical cases, the beginning of the history of a system is the determination of the initial condition $\boldsymbol{H}_{0}$. Changes in the outcome function $O_{t}$, reflecting the evolution of the environment, affect the system through structural parameters. Since the system is open, exogenous and stochastic factors affect both the initial condition and the structural parameters of the model.

\section{Path dependence in conventional economics - a linear model of the Samuelson-Hicks trade cycle}

\subsection{Basic equations of the model}

Path dependence appears many times in the wellknown work by J.M. Keynes, The General Theory of Employment, Interest, and Money, which formed the basis for development of modern macroeconomics [24, 25]. The conventional Samuelson-Hicks model contains formalization of the key concepts of Keynesian economics in the form of a linear dynamic system [26-29]. At the same time, it should be treated as a milestone in the development of conventional economics, since it combines the problems of economic fluctuations and dynamic growth. This is possible through assuming that autonomous investments, being the only manifestation of state intervention in the economy, increase according to a certain fixed percentage rate. The basic equations of the model have the following forms:

$$
\begin{aligned}
& Y_{t}=I_{t}+C_{t} ; \\
& I_{t}=I_{t}^{\text {ind }}+I_{t}^{\text {aut }} ; \\
& C_{t}=c Y_{t-1}, \quad 0<c \leq 1, \quad c=1-s ; \\
& I_{t}^{\text {ind }}=v\left(Y_{t-1}-Y_{t-2}\right), \quad v=\text { constans }, \quad v>0 ; \\
& I_{t}^{\text {aut }}=A_{0}(1+r)^{t}, A_{0}, r=\text { constans, } A_{0}, r \geq 0 ;
\end{aligned}
$$

where: $Y$ - national income, $I$ - aggregate investments, $C$ - consumption, $I_{t}^{\text {ind }}$ - induced investments, $I_{t}^{\text {aut }}$ - autonomous investments, $c$ - marginal propensity to consume, $s$ - marginal propensity to save, $v$ acceleration coefficient, $A_{0}$ - initial level of autonomous investments, $r$ - rate of growth of autonomous expenditures. It may seem that path dependence in this model is restricted to two successive time steps present only in the term describing induced investments. However, as it has been previously explained, there are no impediments to using definition (1) and (2).

National income in period $t$, taking into account Eqs. (3)-(7), can be written in the following form:

$$
Y_{t}=c Y_{t-1}+v\left(Y_{t-1}-Y_{t-2}\right)+A_{0}(1+r)^{t}
$$

or in an equivalent form:

$$
Y_{t}-(c+v) Y_{t-1}+v Y_{t-2}=A_{0}(1+r)^{t} .
$$

It is a non-homogeneous second order linear difference equation with constant coefficients. To solve it, a particular integral must be determined, which presents the path of dynamic equilibrium, along with the complementary function which determines deviation $Y_{t}$ from the trend $\overline{Y_{t}}$, i.e. $Y_{t}-\overline{Y_{t}}$.

Equilibrium trajectory depends on the course of autonomous investments in time [30]. Usually, three cases are considered:

1. If there are no autonomous expenditures, i.e. $I_{t}^{\text {aut }}=0$, then the solution of Eq. (9), describing herein the system in dynamical equilibrium, takes the following form:

$$
\overline{Y_{t}}=\overline{Y_{0}}(1+r)^{t} \text {. }
$$

At the same time, the principle of the so-called strong accelerator is applied:

$$
v>(1+\sqrt{s})^{2} .
$$

In this case, the dynamic equilibrium path (10) is a particular solution of Eq. (9), which can be proved by substituting (10) to (9). Condition (11) means that in such a situation we are dealing with an even growth of national income.

2. For an even growth of autonomous investments, following according to Eq. (7), we also have an dynamic equilibrium path described by Eq. (10), while the socalled super multiplier principle must be satisfied:

$$
\frac{\overline{Y_{0}}}{A_{0}}=\frac{1}{1-\frac{c+v}{1+r}+\frac{v}{(1+r)^{2}}} .
$$

Super multiplier is a term referring to combined effects of a multiplier and the principle of acceleration [30].

3. In the classical theory of economics, we can also deal with forced (exogenous) oscillations of autonomous investments, which are regular and have a constant amplitude:

$$
I_{t}^{\text {aut }}=A_{0} \cos \left(k t-k_{0}\right), \quad k=2 \pi / T,
$$

where: $A_{0}$ - oscillation amplitude; $T$ - period of the autonomous investments; $k_{0}$ - oscillation phase. If the solution of Eq. (9) also contains oscillations, which occurs for 


$$
(1-\sqrt{s})^{2}<v<(1+\sqrt{s})^{2}
$$

and the period of oscillation of autonomous investments is longer than the period of internal oscillation of the model, then the particular integral takes the following form:

$$
\overline{Y_{t}}=\overline{Y_{0}} \cos \left(k t-\vartheta_{0}\right),
$$

if the following condition is satisfied:

$$
\begin{gathered}
\overline{Y_{0}} \cos \left(k t-\vartheta_{0}\right)-(c+v) \overline{Y_{0}} \cos \left[k(t-1)-\vartheta_{0}\right] \\
+v \overline{Y_{0}} \cos \left[k(t-2)-\vartheta_{0}\right]=A_{0} \cos \left(k t-k_{0}\right),
\end{gathered}
$$

where $\vartheta_{0}$ is a phase shift. More information concerning this case can be found in the literature on the subject [30].

A complementary function is determined on the basis of the roots of the following characteristic equation:

$$
\lambda^{2}-(c+v) \lambda+v=0 .
$$

Its solution allows all possible cases of deviations of national income from the dynamic equilibrium level to be determined. After taking into account relation (17), we obtain a complete description of the dynamics of the system determined by Eqs. (3)-(7).

\subsection{Path dependence in a weak version}

The solution of Eq. (17) determines sets of points situated on a plane $(v, s)$, which determine basic types of evolution of national income over time $[30,31]$. In the economic system determined by Eqs. (3)-(7), five types of dynamics can be distinguished:

1. $v \leq(1-\sqrt{s})^{2}$ - asymptotic approach to the dynamic equilibrium level $\overline{Y_{t}}$, $Y_{t}$

2. $(1-\sqrt{s})^{2}<v<1-$ damped oscillation around

3. $1<v<(1+\sqrt{s})^{2}$ - growing oscillation amplitude,

4. $v \geq(1+\sqrt{s})^{2}$ - explosive income growth without oscillation,

5. $v=1$ - regular oscillation with a constant amplitude.

Omitting case 5, which should be considered as unrealistic, the remaining cases can be divided into two groups:

$\mathrm{I} \Rightarrow v<1-$ damped or suppressed movements,

II $\Rightarrow v>1$ - explosive movements.

Figure 1 presents an example course of suppressed and exploding movements. If $v<1$, then we deal with an approach to the dynamic equilibrium path, and if $v>1$, then the system attractor is a point in infinity. In both cases, since definition (1) is satisfied, in the model determined by Eqs. (3)-(7) path dependence exists in a weak version. National income in period $t+1$, i.e. $Y_{t+1}$, depends on income in period $t: Y_{t+1}=O_{t}\left(Y_{t}\right)$. The vector of historical events is created by chronologically-ordered national income volumes in individual periods, starting from the zero period volume, i.e. $\boldsymbol{H}_{t}=\left[Y_{0}, Y_{1}, \ldots, Y_{t-1}\right]$. Empirical research confirms that cumulated economic growth in a specified time period depends on the entire vector of history covering this period, and not only on the initial and final values $\boldsymbol{H}_{t}[32]$. In particular, historical relations play a significant role in long periods, including intervals from 30 to 40 years.
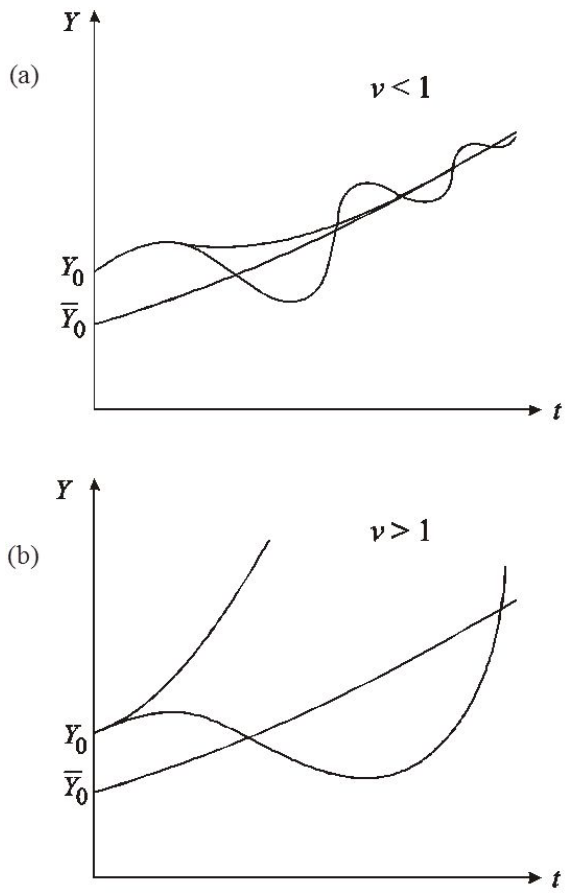

Fig. 1. Typical trajectories of national income: (a) suppressed (or damped) movements for $v<1$ and

(b) exploding movements for $v>1$.

A weak version of path dependence does not exclude asymptotic convergence of the outcome functions for two different vectors of history. Definition (1) also points to another phenomenon, which is not properly emphasized in conventional economics. The rate and the variety of economic processes existing within various vectors of history are determined mainly by the parameter values. The importance of initial conditions is not properly brought up, as is the case in complexity economics.

\section{Path dependence in complexity economics - the neoclassical model of economic growth modified by Day}

\subsection{Model formulation}

The considered dynamic process is described with the use of one-dimensional irreversible mapping. This type of mapping represents the simplest systems, which are capable of generating complex dynamics in the form of deterministic chaos. Since many phenomena which occur in multidimensional systems can also occur in onedimensional mappings, the latter provide a basic pattern for dynamic system transformations. One-dimensional irreversible mappings feature basic chaos scenarios (route to chaos) and major bifurcation phenomena [33].

The basis for these reflections is the standard neoclassical growth model by Solow, formulated in a discrete version with constant marginal propensity to save [34]. 
Let us consider the economy described by the following set of equations:

$$
\begin{aligned}
& Y_{t}=C_{t}+I_{t}, \\
& I_{t}=K_{t+1}, \\
& S_{t}=Y_{t}-C_{t}=s Y_{t}, \quad s>0, \\
& Y_{t}=F\left(K_{t}, L_{t}\right), \\
& L_{t}=(1+n)^{t} L_{0}, \quad n>0,
\end{aligned}
$$

where symbols $Y, C, I, K, S, L$ mean, respectively, national income, consumption, investment, capital, savings, and labour, $s$ is the marginal propensity to save and $n$ is the natural rate (rate of growth of labour force). The symbol $F$ represents a production function, thus the method in which production factors, $K_{t}$ and $L_{t}$, are transformed into the national income $Y_{t}$. Additionally, in each period $t$, the condition of economic equilibrium $S_{t}=I_{t}$ is satisfied.

The neoclassical theory usually applies a linear and homogeneous production function, characterized by constant returns in relation to scale:

$$
F(\lambda K, \lambda L)=\lambda F(K, L) \text { for } \lambda>0,
$$

This means production growth in the same proportions as labour and capital inputs. The function of this type is equal to a single variable function, considered in per capita terms:

$$
\begin{aligned}
& Y=F(K, L)=L f\left(\frac{K}{L}\right), \\
& \text { where } f\left(\frac{K}{L}\right)=F\left(\frac{K}{L}, 1\right),
\end{aligned}
$$

therefore, $y=f(k)$, where $y=\frac{Y}{L}$ and $k=\frac{K}{L}$. Additionally, such a function should be well-behaved [35], which means satisfaction of the following conditions:

$$
f^{\prime}(k)>0, \quad f^{\prime \prime}(k)<0, \quad f^{\prime}(k) \rightarrow \infty,
$$$$
\text { gdy } k \rightarrow 0, \quad f^{\prime}(k) \rightarrow 0, \text { gdy } k \rightarrow \infty \text {. }
$$

A linear and homogeneous production function allows the described model to be presented by Eqs. (18)-(22) in the following form:

$$
\frac{K_{t+1}}{L_{t}}=\frac{s F\left(K_{t}, L_{t}\right)}{L_{t}} \Rightarrow k_{t+1}(1+n)=s f\left(k_{t}\right) .
$$

Detailed information concerning the transformation of Eqs. (18)-(22) into relation (26), with the use of assumptions $(23)-(25)$ can be found in the literature $[35,36]$. With conventional assumptions (23)-(25), the solution of Eq. (26) is an asymptotically stable fixed point:

$$
k^{*}=\frac{s f\left(k^{*}\right)}{1+n} .
$$

For example, for the production function of the CobbDouglas type, $f(k)=B k_{t}^{\beta}$, all system trajectories are convergent to the path of balanced growth:

$$
k^{*}=\left(\frac{s B}{1+n}\right)^{\frac{1}{1-\beta}} .
$$

Coefficient $B$ may be interpreted as the level of technology, while $\beta>0$.
Day $[36,37]$ proposes the introduction to the neoclassical Cobb-Douglas type production function of an additional, multiplicative element $\left(m-k_{t}\right)^{\phi}$ related to efficiency reduction:

$$
y_{t}=\frac{Y_{t}}{L_{t}}=f\left(k_{t}\right)=B k_{t}^{\beta}\left(m-k_{t}\right)^{\phi}, \quad k_{t} \leq m,
$$

where $m, \phi$ are positive parameters. The economic growth and accompanying concentration of capital result in the emergence of social costs, related mainly to degradation of the natural environment. An additional expression presents the effect of the pollution emission on production per capita. A rational management of resources will help to avoid an increase in pollution, but production growth will then be reduced. If coefficient $\phi$ is close to zero, then $\left(m-k_{t}\right)^{\phi} \rightarrow 1$. Parameter $m$ corresponds to a certain level of saturation, the reaching of which $\left(k_{t}=m\right)$ will cause a production decrease to zero. From the perspective of environmental protection programmes, coefficients $m$ and $\phi$ can be treated as control parameters.

Both the neoclassical production function of CobbDouglas and its modification proposed by Day are examples of power laws. They emerged in economic sciences for the first time at the end of 19th century as a result of discoveries made by an Italian economist, Vilfredo Pareto, who examined the distributions of income in various societies [38-39]. The dependence he discovered significantly differed from the Gaussian bell curve, and additionally demonstrated high stability in space and time: the shape of the distribution looked similar for various countries and eras. In the opinion of Pareto, the curve of income distribution is an external image of a given society and a basic factor of its internal transformations. Apparently, the same can be true for the production functions of Cobb-Douglas and Day.

Inclusion of a production function (29) to the growth model (18)-(22) results in a difference equation:

$$
k_{t+1}=\frac{s B}{1+n} k_{t}^{\beta}\left(m-k_{t}\right)^{\phi} .
$$

By introducing a new parameter $\mu=\frac{s B}{1+n}$, we finally obtain a nonlinear first order difference equation:

$$
k_{t+1}=\mu k_{t}^{\beta}\left(m-k_{t}\right)^{\phi}=F(k),
$$

which will be subject to computer simulations.

After taking into account power laws in the model (31), its dynamic characteristics become completely different from the previously-analysed conventional case. As it will be demonstrated in the further part of the article, path dependence is satisfied here both in the weak version (1) and in the strong one (2). This is caused by the fact that the production functions of Cobb-Douglas and Day introduce nonlinearity to the model in the form of a double power law. Consequently, attractors in the form of attracting fixed points and repellers in the forms of repelling fixed points appear in the phase space of the model. The co-existence of three fixed points in a configuration where a point repeller is situated between two point attractors leads to strong path dependence 
(and thus to path dependence). The dynamics of system (31), determined by initial conditions and values of parameters, may be also more complex.

Function (31) has the bell shape with a single maximum, which can be determined by comparing the first derivative to zero:

$$
k_{\max }=\frac{\beta m}{\beta+\phi},
$$

therefore,

$$
F\left(k_{\max }\right)=\mu\left(\frac{m}{\beta+\phi}\right)^{\beta+\phi} \beta^{\beta} \phi^{\phi} .
$$

The zeroes are as follows: $F(0)=0$ and $F(m)=0$. To avoid negative values of capital stock per capita, it is required that $F\left(k_{\max }\right) \leq m$, therefore coefficients have to satisfy the following condition:

$$
\mu\left(\frac{m}{\beta+\phi}\right)^{\beta+\phi} \beta^{\beta} \phi^{\phi} \leq m .
$$

In practice, it is not difficult to satisfy condition (34) since, in the real world, the value of parameter $\mu$ is significantly lower than one. Otherwise, we would have to deal with such devastation of the natural environment that would involve a highly rapid decrease in the production rate of capital goods. Although this would certainly threaten the existence of the economic system, fortunately, under normal conditions, such a phenomenon has not yet been observed.

\subsection{Weak path dependence}

The neoclassical model modified by Day has a certain interesting property. Mapping (31) has a fixed point of zero, which is the most common attracting fixed point. After calculating the derivative

$$
F^{\prime}(k)=\mu \beta k^{\beta-1}(m-k)^{\phi}-\mu k^{\beta} \phi(m-k)^{\phi-1}
$$

we can see that $F^{\prime}(0)=0$ (for $\beta \neq 1$ ). Numerical explorations have shown that if we assume an initial point of $k_{0}=0.4$ and establish that $\mu=3.9, m=1.45$, $1.3<\phi<10,1.2<\beta<2.9$, then two point attractors may coexist in a phase space of the model and zero is one of them [40]. The zero attractor can coexist with other objects, such as unstable fixed points, or can be the only attractor of the system.

Let $\mu=3.9, \beta=2.19, m=1.45, \phi=8.66$, and the initial point remains unchanged. We then have three fixed points $k_{1}^{c}=0, k_{2}^{c} \approx 0.024$ and $k_{3}^{c} \approx 0.514$; the last two being unstable:

$$
\left|F^{\prime}\left(k_{2}^{c}\right)\right|,\left|F^{\prime}\left(k_{3}^{c}\right)\right|>1 .
$$

Figure 2 presents a system trajectory obtained by the cobweb method. A graph of mapping (31) intersects a line inclined at $45^{\circ}$ in two points: $k_{2}^{c}$ and $k_{3}^{c}$. The trajectory starts at point $x_{0}=0.4$ and after a few dozen iterations in the $0<k<1$ range it approaches zero. Figure 2a presents a general course near point $k_{3}^{c}$ and an arrow marks one of last iterations before reaching zero. Figure $2 \mathrm{~b}$ presents an enlarged fragment of a graph in Fig. 2a and shows the changes occurring in the system near point $k_{2}^{c}$. An arrow marks a continuation of the last stage of the trajectory presented in Fig. 2a.

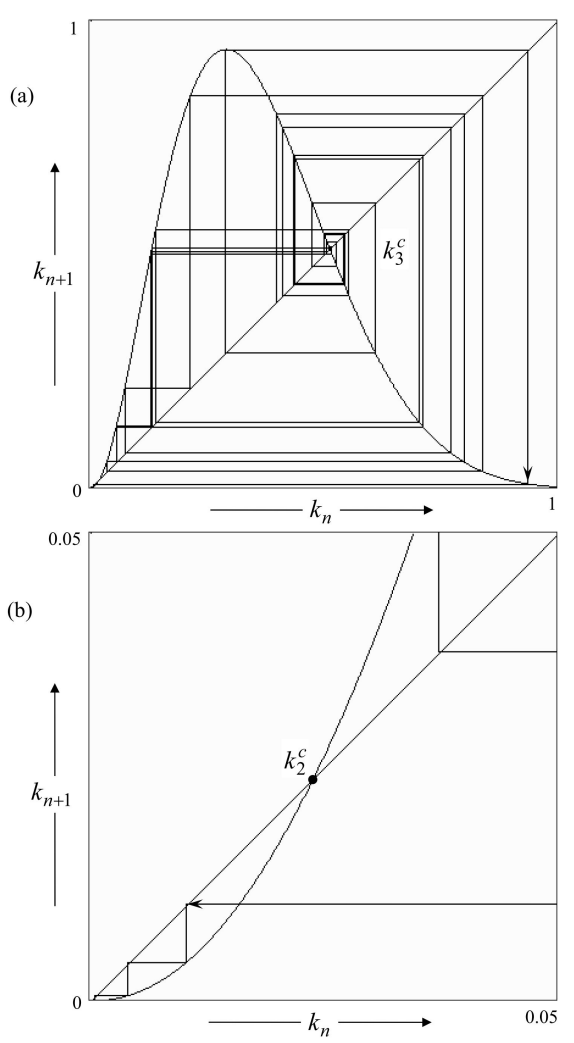

Fig. 2. Trajectory of the neoclassical growth model for $k_{0}=0.4, \mu=3.9, \beta=2.19, m=1.45, \phi=8.66$, approaching a fixed point of zero: (a) general view of the trajectory, (b) enlargement of the origin of the coordinate system with a fixed point $k_{2}^{c} \approx 0.024$.

Numerical explorations demonstrated that for other initial conditions, although the trajectories of the system were different, zero was an attracting fixed point in each case. This points to the existence of a weak version of path dependency in the economic system (31), since

$x_{t+1}=O_{t}\left(\boldsymbol{H}_{t}\right)$, but for $\boldsymbol{H}_{t} \neq \overline{\boldsymbol{H}}_{t}$,

we have $O_{t}\left(\boldsymbol{H}_{t}\right) \cong O_{t}\left(\overline{\boldsymbol{H}}_{t}\right)$.

This solution only partially corresponds to the neoclassical theory of economic growth, which provides for the existence of distinguished states or equilibrium paths independent of the history of the system. In the examined case, such independence can be referred to only in a global sense. From the economic point of view, such a solution is surprising, since it means liquidation of the existing method of management. On the other hand, in the local sense, differences in initial conditions lead to different histories, which implies weak path dependence. Additionally, the lengths of the vectors of history $h_{t}$, which are measured by the number of iterations, were different for various initial conditions. Global independence of the zero state on the history of the system is of little practical importance, since economy is an open dynamical 
system. Therefore, in a sufficiently long time, environment impacts may appear which, through the change of parameters, amend the nature of the system and reverse the negative trends (divergence of the trajectory to zero).

A slightly different possibility is presented in Fig. 3, in which the path of the system for the following values of parameters is drawn: $\mu=3.9, \beta=2.87, m=1.45$ and $\phi=2.9$. Since a graph of mapping does not intersect the diagonal $F(k)=k$ at all, therefore, the only attracting fixed point is zero and the trajectory starting in point $k_{0}=0.4$ approaches it. From the point of view of path dependence relations, there is no significant difference in comparison to the previous case. Definition (37) is satisfied. Different vectors of history occur for different initial conditions, although the global independence of an attracting fixed point from the system history emerges. However, an interesting regularity can be observed. The length of the vectors of history $h_{t}$ directly depend on the initial conditions. The higher the value of the initial capital per capita, the longer the system destruction is.

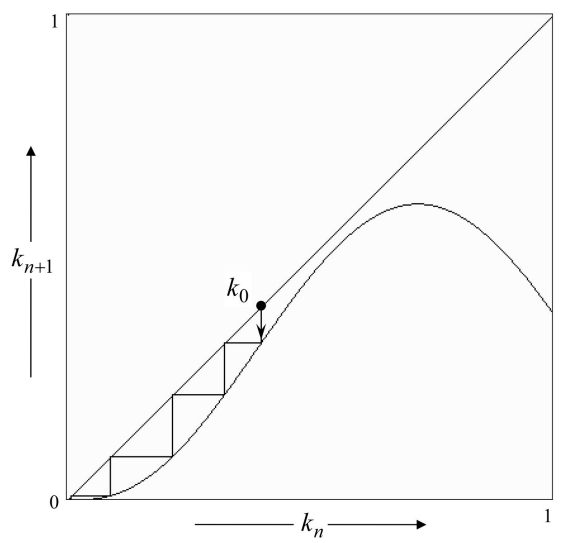

Fig. 3. Trajectory of mapping (31) initiated in point $k_{0}=0.4$ approaching the fixed point of zero. No other fixed points $(\mu=3.9, \beta=2.87, m=1.45$ and $\phi=2.9)$.

The two cases examined above point to the need for a certain modification to the definition of weak path dependence. This should include the length of the vectors of history, which in the examined model depends on the initial conditions. However, we still have two possibilities. The first is that the final point can be the same for various vectors of history, which may have different lengths in terms of the number of iterations. The second possibility indicates various target states for various vectors, while again, the length of individual vectors can be different. In the second case, we enter a strong path-dependencetype relationship, which will be discussed below.

\subsection{Strong path dependence}

The situation when the zero attractor coexists with another attracting fixed point is slightly different. Let us examine a point in a four-dimensional space of parameters, with the following coordinates $\phi=9.1$ and $\beta=2.9$, $\mu=3.9, m=1.45$. Mapping (31) then has three fixed points: $k_{1}^{c}=0, k_{2}^{c} \approx 0.1285$ and $k_{3}^{c} \approx 0.4157$, while only point $k_{2}^{c}$ is unstable. After substituting those values to Eq. (35), we have:

$$
\left|F^{\prime}\left(k_{2}^{c}\right)\right|>1 \text { and } 0>F^{\prime}\left(k_{3}^{c}\right)>-1 .
$$

Figure 4 presents two examples of trajectories concerning the described case. The first of them starts at point $k_{01}=0.1535$ and aims towards the fixed point $k_{3}^{c} \approx$ 0.4157 , while the other, initiated at point $k_{02}=0.1$ approaches zero. Therefore, we deal in the system with the coexistence of two attractors being fixed points. A path starting at point $k_{0}=0.4$ reaches $k_{3}^{c}$, but already for the initial condition $k_{0}=0.7$ we again have convergence to zero. An attracting fixed point of zero may coexist with a stable periodic orbit with any period and with a chaotic attractor.

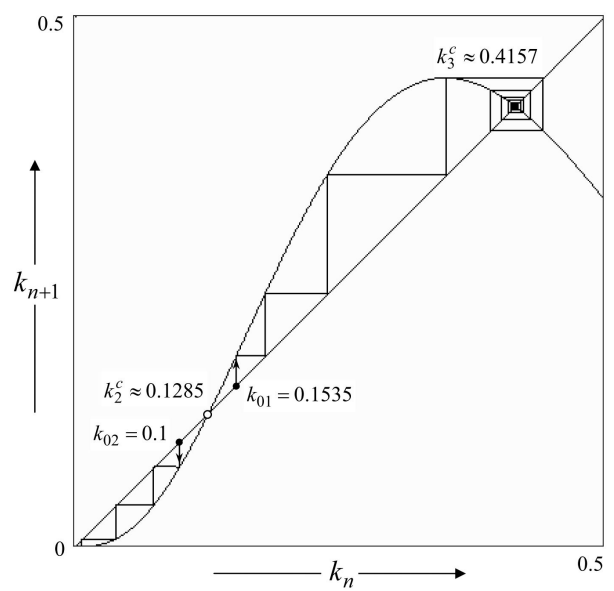

Fig. 4. Coexistence of two attractors of mapping (31) being fixed points. The trajectory initiated in point $k_{01}=0.1535$ is convergent to $k_{3}^{c}$, and the trajectory started in point $k_{02}=0.1$ approaches zero $(\mu=3.9$, $\beta=2.9, m=1.45$ and $\phi=9.1)$.

In the examined case, since definition (2) is satisfied, there is a strong path-dependence-type relationship. Various vectors of history lead to various outcome functions. In the example presented in Fig. 4 we can also see a certain organization of the vectors of history. Initial values of the capital stock per capita, which determine individual vectors of history, belong to two disjointed sets. The first set contains initial conditions whose paths are convergent to zero, while the other set contains initial conditions whose paths are convergent to an attracting fixed point different than zero. In this way, basins of attraction of these attractors have been defined. Additionally, the structure of these sets is complex, as they intermingle. The attractor of zero also emerges for start points satisfying the condition $k_{0}>k_{2}^{c} \approx 0.1285$. Thus, we can see that strong path dependence in dynamical systems is related to the coexistence of various attractors, and their basins of attraction define various vectors of history. 
The neoclassical model of economic growth supplemented with two power laws, the production function of the Cobb-Douglas type and a multiplicative element reflecting the impact of pollution on economic growth, contains all important elements of neoclassical economics. Therefore, it can be considered a milestone in the history of economic thought. It was formulated at the beginning of $1980 \mathrm{~s}$, but has not yet been subject to thorough dynamic research. Perhaps the academic community has decided that it has already satisfied its basic task, which was the introduction of complexity to economics. Models such as this one have certainly made researchers aware of the role of nonlinearity and deterministic chaos in economics. Unfortunately, they were later a bit forgotten. This article makes an attempt to fill the existing gap and presents an in-depth analysis of system (31), taking into account various initial values and parametric sensitivity issues. This led to discovery of previously unknown dynamic features of the model, such as the co-existence of attractors and repellers and the occurrence of path dependence in a weak and strong version.

\section{Conclusions}

Traditional economics, based on linear conventional models, reveal a path-dependence relation in a weak version. This is related to the existence of only two types of attractors: either a dynamic state of equilibrium, or a point in infinity, to which system trajectories are asymptotically convergent, regardless of the initial conditions. In conventional economics, the rate and variety of events within various vectors of history mainly depend on the parameter values. Complexity economics, taking into account nonlinear phenomena, broadens the catalogue of types of behaviour demonstrated by markets and economies. A strong path dependence already exists in simple one-dimensional nonlinear systems, as shown by a modified version of the Solow model of economic growth. Path dependence, regardless of whether it is considered in a weak or strong version, should not be identified with deterministic chaos. The neoclassical model of economic growth also confirms the existence of a weak version this relation, while the lengths of the vectors of history do not depend only upon the value of parameters - as in the case of conventional models but upon initial conditions.

The results of computer simulations of dynamic changes in the neoclassical model are slightly surprising. According to Eq. (31), a decrease of $\phi$ to zero guarantees that a multiplicative element $\left(m-k_{t}\right)^{\phi}$ will approach unity and the production function (29) will be similar to the traditional Cobb-Douglas function $f(k)=B k_{t}^{\beta}$ [41]. In addition, a known solution in the form of a sustainable growth path can be expected. However, a decrease in parameter $\phi$ causes quite unexpected changes in system behaviour (31). If $\beta=2.15$ and $\phi=10$, then the trajectory is convergent to zero, since it is the only attracting fixed point.
In light of the above results, economic interpretation of the neoclassical model seems to be a crucial issue. I do not suppose that the convergence of the trajectory to zero would reduce its applicability, since reaching this state requires time and, consequently, the performance of a certain number of iterations. Such a path can be considered equivalent to impermanent, temporary production methods. Also, not everything depends on the value of parameters. The system has certain restrictions imposed on initial conditions: only specific initial forms have an opportunity to develop, and not all of them. The situation presented in Fig. 4, where a repelling fixed point occurs between two stable fixed points, may prove the existence of a growth barrier difficult to be overcome for less developed countries (starting from a lower level). On the other hand, if the limit $k_{2}^{c} \approx 0.1285$ is crossed, then the economic system will reveal flexibility and an ability to survive, even if stable cycles or chaotic behaviour emerge. However, high initial values are also not desirable, as such gigantomania leads to the decline of the system (the basins of attraction of both attractors intermingle). Coexistence of attractors can also indicate the frailty of contemporary economies, since their survival depends on an appropriate combination of parameter values. A zero attractor represents the potential threat of a decline of the present method of management based on uncontrolled use of resources and leading to environmental pollution. Analogically, divergent trajectories can be treated as forbidden states of the system. The ranges determined by parameters and initial conditions in which the system can exist and develop are not too broad. To summarize, it seems that this simple nonlinear model is highly useful for describing reality.

In so far as the phenomenon of path dependence is one of the basic features of complex dynamic systems which in the hard sciences are subject to formalization and analyses in a quantitative way, the issue of historical conditions in economics and social sciences is examined almost entirely with the use of qualitative methods. Path dependence ideas are used mainly for describing advanced technology markets where the causes of market failures and the emergence of monopolies offering non-optimal solutions are analysed. One of the best known examples is the QWERTY layout keyboard, which is less efficient for typing in comparison to other, better but lesser-known solutions. For these reasons, the study of path dependence in economics is still in the non-formalized phase. This article is one of the first theoretical attempts to establish necessary foundations for empirical analyses of path dependence phenomena in economics. It also shows another inventive application of path dependence, consisting in an analysis of risks resulting from environmental pollution.

\section{Acknowledgments}

I would like to thank the anonymous reviewer for indepth and detailed comments concerning the original version of the text. 


\section{References}

[1] W.B. Arthur, Complexity Economics: A Different Framework for Economic Thought, Santa Fe Institute Working Paper: 2013-04-012 (2013).

[2] S.N. Durlauf, What Should Policymakers Know About Economic Complexity?, Santa Fe Institute Working Paper: 97-10-080 (1997).

[3] W.B. Arthur, Increasing Returns and Path Dependence in the Economy, University of Michigan Press, Ann Arbor 1994.

[4] C. Antonelli, Path Dependence, Localized Technological Change and the Quest for Dynamic Efficiency, in: New Frontiers in the Economics of Innovation and New Technology: Essays in Honour of Paul A. David, Eds. C. Antonelli, D. Foray, B.H. Hall, W.E. Steinmueller, Edward Elgar Publishing, Cheltenham 2006, p. 51.

[5] W. Kwaśnicki, Skanalizowane ścieżki rozwoju przemystu, XX Szkoła Symulacji Systemów Gospodarczych, Polanica Zdrój 2003.

[6] P.A. David, Path Dependence, its Critics and the Quest for 'Historical Economics', in: Evolution and Path Dependence in Economic Ideas: Past and Present, Eds. P. Garrouste, S. Ioannides, Edward Elgar Publishing, Cheltenham 2001, p. 15.

[7] S.J. Liebowitz, S.E. Margolis (Eds.), Path Dependence and Lock-In, Edward Elgar Publishing, Cheltenham 2014.

[8] R. Martin, P. Sunley, The Place of Path Dependence in an Evolutionary Perspective on the Economic Landscape, in: The Handbook of Evolutionary Economic Geography, Eds. R. Boschma, R. Martin, Edward Elgar Publishing, Cheltenham 2010, p. 62.

[9] J. Koch, M. Eisend, A. Petermann, Bus. Res. 2, 67 (2009).

[10] C. List, Am. Polit. Sci. Rev. 98, 495 (2004).

[11] P. Malpass, Housing, Theory and Society 28, 305 (2011).

[12] C. Castaldi, G. Dosi, E. Paraskevopoulou, Path Dependence in Technologies and Organizations: A Concise Guide, Working Paper 11.04, Eindhoven Centre for Innovation Studies, School of Innovation Sciences, Eindhoven University of Technology, Eindhoven 2011.

[13] K.J. Meier, R.D. Wrinkle, S. Robinson, J.L. Polinard, Path Dependence and Organizational Performance: Representative Bureaucracy, Prior Decisions, and Academic Outcomes, 59th National Meeting of the Midwest Political Science Association, Chicago 2001.

[14] I. Greener, Theorising Path Dependence: How does History Come to Matter in Organisations, and what Can We Do about It?, Working Paper 3, Department of Management Studies, University of York, York 2004.

[15] B. Ebbinghaus, Can Path Dependence Explain Institutional Change? Two Approaches Applied to Welfare State Reform, Discussion Paper 05/2, Max Planck Institute for the Study of Societies, Cologne 2005.

[16] R. Hochreiter, G.Ch. Pflug, Computational Economics 28, 291 (2006).

[17] J. Mahoney, Theory and Society 29, 507 (2000).
[18] P. Pierson, Am. Polit. Sci. Rev. 94, 251 (2000).

[19] L. Dobusch J. Kapeller, Schmalenbach Business Review 65, 288 (2013).

[20] J.-P. Vergne, R. Durand, J. Manage. Stud. 47, 736 (2010).

[21] J. Sydow, A. Windeler, G. Müller-Seitz, K. Lange, Bus. Res. 5, 155 (2012).

[22] R.I. Khrapko, Path-Dependent Functions, Theor. Math. Phys. 65, 1196 (1985).

[23] S.E. Page, Q. J. Political Science 1, 87 (2006).

[24] J.M. Keynes, The General Theory of Employment, Interest, and Money, 5th ed., MacMillan, London 1946.

[25] A. Herscovici, Nature of Capital, Long-Run Expectations and Path Dependence in the General Theory: Some Epistemological Observations, The Third Nordic Post-Keynesian Conference, Aalborg University, Aalborg 2014.

[26] P.A. Samuelson, A Synthesis of the Principle of Acceleration and the Multiplier, J. Polit. Econ. 47, 786 (1939).

[27] P.A. Samuelson, Rev. Econ. Stat. 21, 75 (1939).

[28] A. Jakimowicz, Analiza porównawcza teorii cyklu koniunkturalnego $w$ ujęciu J.M. Keynesa $i$ P.A. Samuelsona [A Comparative Analysis of J.M. Keynes' and P.A. Samuelson's Business Cycle Theories], Wydawnictwo Adam Marszałek, Torun 1991.

[29] J.R. Hicks, A Contribution to the Theory of the Trade Cycle, Clarendon Press, Oxford 1951.

[30] A. Jakimowicz, Od Keynesa do teorii chaosu. Ewolucja teorii wahań koniunkturalnych [From Keynes to Chaos Theory. Evolution of Business Cycle Theories], Wydawnictwo Naukowe PWN, Seria: "Współczesna Ekonomia", Warszawa 2012.

[31] R.G.D. Allen, Ekonomia matematyczna, PWN, Warszawa 1961

[32] J. Bellaïche, J. Math. Econ. 46, 163 (2010).

[33] E. Ott, Chaos in Dynamical Systems, 2nd ed., Cambridge University Press, Cambridge 2002.

[34] R.M. Solow, Q. J. Econ. 70, 65 (1956).

[35] R.G.D. Allen, Teoria makroekonomiczna. Ujęcie matematyczne, PWN, Warszawa 1975.

[36] R.H. Day, Am. Econ. Rev. 72, 406 (1982).

[37] R.H. Day, The Emergence of Chaos from Classical Economic Growth, Q. J. Econ. 98, 201 (1983).

[38] V. Pareto, Cours d'économie politique, vol. 1-2, in: Oeuvres complètes, Eds. G.-H. Bousquet, G. Busino, vol. 1, Librairie Droz, Genève 1964.

[39] V. Pareto, Manual of Political Economy, Macmillan, London 1971.

[40] A. Jakimowicz, Podstawy interwencjonizmu państwowego. Historiozofia ekonomii [Foundations of State Interventionism: Philosophy of Economics History], Seria: Współczesna Ekonomia, Wydawnictwo Naukowe PWN, Warszawa 2012.

[41] G. Abraham-Frois, Dynamique économique, Dalloz, Paris 1995. 